\title{
Validation of an RNA cell cycle progression score for predicting death from prostate cancer in a conservatively managed needle biopsy cohort
}

J Cuzick $^{*}, 1$, S Stone ${ }^{2}$, G Fisher ${ }^{1}$, Z H Yang ${ }^{1}$, B V North ${ }^{1}$, D M Berney ${ }^{3}$, L Beltran $^{3}$, D Greenberg ${ }^{4}$, H Møller $^{5}$, J E Reid ${ }^{2}$, A Gutin ${ }^{2}$, J S Lanchbury ${ }^{2}$, M Brawer ${ }^{2}$ and P Scardino ${ }^{6}$ on behalf of the Transatlantic Prostate Group ${ }^{1}$ Centre for Cancer Prevention, Wolfson Institute of Preventive Medicine, Queen Mary University of London, London, UK; ${ }^{2}$ Myriad Genetics, Inc., Salt Lake City, UT, USA; ${ }^{3}$ Department of Molecular Oncology, Barts Cancer Institute, Queen Mary University of London, London, UK; ${ }^{4}$ National Cancer Registration Service (Eastern Office), Public Health England, Cambridge, UK; ${ }^{5}$ Cancer Epidemiology and Population Health, King's College London, London, UK and 'Department of Urology, Memorial SloanKettering Cancer Center, New York, NY, USA

Background: The natural history of prostate cancer is highly variable and difficult to predict accurately. Better markers are needed to guide management and avoid unnecessary treatment. In this study, we validate the prognostic value of a cell cycle progression score (CCP score) independently and in a prespecified linear combination with standard clinical variables, that is, a clinical-cellcycle-risk (CCR) score.

Methods: Paraffin sections from 761 men with clinically localized prostate cancer diagnosed by needle biopsy and managed conservatively in the United Kingdom, mostly between 2000 and 2003. The primary end point was prostate cancer death. Clinical variables consisted of centrally reviewed Gleason score, baseline PSA level, age, clinical stage, and extent of disease; these were combined into a single predefined risk assessment (CAPRA) score. Full data were available for 585 men who formed a fully independent validation cohort.

Results: In univariate analysis, the CCP score hazard ratio was $2.08\left(95 \% \mathrm{Cl}(1.76,2.46), P<10^{-13}\right)$ for one unit change of the score. In multivariate analysis including CAPRA, the CCP score hazard ratio was $1.76\left(95 \% \mathrm{Cl}(1.44,2.14), P<10^{-6}\right)$. The predefined CCR score was highly predictive, hazard ratio $2.17\left(95 \% \mathrm{Cl}(1.83,2.57), \chi^{2}=89.0, P<10^{-20}\right)$ and captured virtually all available prognostic information.

Conclusions: The CCP score provides significant pretreatment prognostic information that cannot be provided by clinical variables and is useful for determining which patients can be safely managed conservatively, avoiding radical treatment.

The natural history of prostate cancer is highly variable and difficult to predict accurately. Better markers are needed to guide management and avoid unnecessary treatment. This is exacerbated by PSA screening, which identifies a greater number of indolent cancers. PSA screening is not recommended in most European countries and recently the US Preventive Services Task Force recommended against population-based screening with PSA (Moyer and U.S. Preventive Services Task Force, 2012) owing to

*Correspondence: Professor J Cuzick; E-mail: j.cuzick@qmul.ac.uk

Received 12 February 2015; revised 12 May 2015; accepted 25 May 2015;

published online 23 June 2015

(C) 2015 Cancer Research UK. All rights reserved 0007 - 0920/15

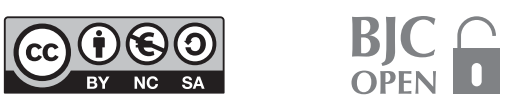


two large prospective trials one of which showed a $21 \%$ reduction in prostate cancer mortality while the other found no effect (Andriole et al, 2009; Schröder et al, 2012).

Although these trials came to different conclusions about the efficacy of PSA screening, there is general agreement that better strategies for avoiding overtreatment of early cancers are needed (Cuzick et al, 2014) before screening can be widely adopted. Current management decisions are guided largely by Gleason score, baseline PSA level, clinical stage, and extent of disease based on core biopsies, and these have been summarised in clinical scores, such as CAPRA (Cooperberg et al, 2005), the Kattan nomogram (Kattan et al, 2008), and the Cuzick score (Cuzick et al, 2006). Although these predictions are valuable, a large number of patients with clinically localised disease are left with an intermediate prognosis (Albertsen et al, 1998, 2005; Cooperberg et al, 2005; Cuzick et al, 2006; Kattan et al, 2008; Cooperberg et al, 2009), and there is considerable uncertainty about their need for radical treatment.

Independent of whether a cancer is diagnosed via screening or symptomatically, active surveillance is becoming the standard care for many men with clinically localised prostate cancer. This makes it even more important to develop biomarkers that can be evaluated in needle biopsies before a decision is made about radical therapy.

Previously, it has been shown that a cell cycle progression (CCP) score added a substantial amount of prognostic information to standard clinicopathological markers for a range of prostate cancer outcomes (Cuzick et al, 2011, 2012; Cooperberg et al, 2013; Freedland et al, 2013; Bishoff et al, 2014; Sommariva et al, 2014). The score was predictive for prostate cancer death in conservatively managed men with clinically localised disease diagnosed by either transurethral resection of the prostate (Cuzick et al, 2011) or needle biopsy (Cuzick et al, 2012). Here we present a needle biopsy-based validation study of both the CCP score alone and as part of a prespecified linear combination with standard clinical variables (combined clinical-cell-cycle-risk (CCR) score) for predicting prostate cancer death in a contemporary cohort of men with clinically localised disease who were initially managed conservatively.

\section{MATERIALS AND METHODS}

Patients. Potential cases of prostate cancer were newly identified from three cancer registries in Great Britain and were distinct from those in our earlier cohorts (Cuzick et al, 2006, 2011, 2012), which evaluated the CCP score. Within each region, collaborating hospitals were sought and case notes reviewed. Men were included in this study if they were aged $<76$ years at diagnosis and had clinically localised prostate cancer diagnosed by needle biopsy between 1990 and 2003 inclusively. The median date of diagnosis was May 2002 (IQR January 2001, May 2003). Patients treated by radical prostatectomy or radiation therapy within 6 months of diagnosis were excluded. Additionally, those with objective evidence of metastatic disease (by bone scan, X-ray, radiograph, CT scan, MRI, bone biopsy, lymph node biopsy, pelvic lymph node dissection) or clinical indications of metastatic disease (including pathological fracture, soft tissue metastases, spinal compression, or bone pain), or a PSA measurement $>100 \mathrm{ng} \mathrm{ml}^{-1}$ at or within 6 months of diagnosis were also excluded. Men who had hormone therapy prior to the diagnostic biopsy were also excluded because of the influence of hormone treatment on interpreting Gleason score. We also excluded men who died within 6 months of diagnosis or had $<6$ months of follow-up (Cuzick et al, 2006).

Original histological specimens from the diagnostic procedure were requested and centrally reviewed by a panel of urological pathologists to confirm the diagnosis of adenocarcinoma and to reassign Gleason scores using a contemporary and consistent interpretation of the Gleason scoring system (Epstein et al, 2005; Epstein, 2010).

Follow-up to 31 December 2012 was conducted through the cancer registries. Deaths were divided into those from prostate cancer and those from other causes by registry staff using death certificates only, according to World Health Organisation standardised criteria (WHO, 2010). National ethics approval was obtained from the Northern Multicentre Research Ethics Committee, followed by approval from local ethics committee at each collaborating hospital.

Sample preparation. All samples were processed in a CLIAcertified laboratory at Myriad Genetics (Salt Lake City, UT, USA). Samples consisted of up to $105-\mu \mathrm{m}$ needle biopsy sections. Selected regions of carcinoma were removed from unstained slides by macro-dissection according to the on-site pathologist's instructions. Paraffin was removed using deparaffinisation solution (Qiagen, Valencia, CA, USA). Total RNA was extracted with miRNeasy (Qiagen) as described by the manufacturer.

Total RNA was treated with DNase I (Sigma-Aldrich, St Louis, MO, USA) before cDNA synthesis. High-capacity cDNA Archive Kit (Applied Biosystems, Foster City, CA, USA) was used to convert total RNA into single-strand cDNA as described by the manufacturer. Before measurement of gene expression, the cDNA was preamplified as previously described (Cuzick et al, 2011, 2012), and expression data were generated using TaqMan Low Density arrays (Applied Biosystems). Expression data were recorded as a threshold cycle value, the PCR cycle at which the fluorescence intensity exceeded a predefined threshold, and all samples were tested in triplicate.

CCP score. We attempted to compute the CCP score for each individual where adequate material (i.e., $\geqslant 0.5 \mathrm{~mm}$ linear extent of tumour evident on an adjacent diagnostic H\&E slide (http:// www.prolaris.com/information-for-physicians/pathology/technicalspecifications) was available. A total of 31 predefined CCP genes and 15 housekeeper genes were amplified on one TaqMan Low Density array. The values of each of three replicates of each of the 31 CCP genes were normalised by subtraction of the average of up to 15 non-failed housekeeper genes for that replicate. Samples failed quality assurance if more than two housekeeper genes or more than nine CCP genes were missing, or if the s.d. of the CCP scores across the triplicate was $>0.5$. Full details have been published previously (Cuzick et al, 2012).

Statistical analysis. Survival was analysed with a Cox proportional hazards model. The primary end point was time to death from prostate cancer. Observations were censored on the date of last follow-up or at death from other causes. All events were used for estimating hazard ratios, but follow-up was censored at 10 years for predicting 10-year risks. Covariates were: centrally reviewed Gleason grade, baseline PSA value, clinical stage, extent of disease (proportion of positive cores), age at diagnosis, and initial hormone management.

A previously published score (CAPRA) (Cooperberg et al, 2005) based on Gleason score, PSA, clinical stage, proportion (\%) of positive cores, and age was computed for each patient. The score ranged from 1 to 10 and was considered linearly and in groups. A predefined combined CCR score encompassing both the CAPRA (linear) and CCP scores was calculated as $\mathrm{CCR}=0.39 \times$ CAPRA $+0.57 \times$ CCP. These coefficients were derived from analyses of four previously described prostate cancer cohorts (Brawer et al, 2013)

Two additional risk scores, the Kattan (Kattan et al, 2008) and the Cuzick (Cuzick et al, 2006), which was used in our previous analyses, were also calculated for each patient. Further exploratory 
analyses included testing for proportional hazards, evaluating predictive value in years $0-4,5-9$ and $10+$ separately, and testing for interactions of the CCP score with individual clinical covariates. Statistical analyses were done with STATA (version 12, StataCorp, College Station, TX, USA) and R (version 3.0, The R Foundation for Statistical Computing, Vienna, Austria).

The analysis data set and an analysis plan were prespecified, and all CCP scores were preassigned before the clinical and outcome data were unmasked. All $P$-values and 95\% CIs were two-sided, and $P$-values were based on $\chi^{2}$ statistics with one degree of freedom obtained from partial likelihoods of proportional hazards models, unless otherwise indicated.

\section{RESULTS}

The full cohort comprised 989 men. A total of 145 (15\%) samples had inadequate tumour $(<0.5-\mathrm{mm}$ length on an adjacent $\mathrm{H} \& \mathrm{E}$ section) and a further $83(8 \%)$ failed CCP score quality assurance (Supplementary Figure S1). For those with adequate amounts of tumour visible on the H\&E $(n=844), 90 \%$ produced a CCP score. One patient lacked information about extent of disease, two patients had missing baseline PSA information, and a further 173 were missing clinical stage, leaving 585 with a CCP score and all clinical variables for analysis in the primary analysis cohort (Supplementary Figure S1). The median age at diagnosis was 70.8 years (IQR $(66.5,73.6$ years)). The median follow-up time was 9.52 years (IQR (6.6, 10.8 years), maximum 19.33 years). Tumour characteristics are shown in Table 1 . A total of 100 men (17\%) died from prostate cancer, 168 (29\%) died from other causes, and 317 (54\%) were alive at last follow-up (31 December 2012). The median CCP score was 0.40 (IQR $(-0.10,1.00)$ ).

Univariate analyses. In the primary univariate analysis (Table 1), a one-unit increase in CCP score was associated with a highly significant 2.08-fold increase in the hazard of dying from prostate cancer $\left(95 \%\right.$ CI $\left.(1.76,2.46), \chi^{2}=56.4, P=6.0 \times 10^{-14}\right)$. The 10 -year death rates from prostate cancer were $7 \%$ for those with a CCP score $<0$ and increased to 15,36 , and $59 \%$ for CCP score groups $0-1,1-2$, and $>2$, respectively (Figure 1 ). Similar results were seen if all 761 men with a valid CCP score were analysed $\left(\mathrm{HR}=2.13,95 \% \mathrm{CI}(1.83,2.47), \chi^{2}=76.0, P=2.9 \times 10^{-18}\right)$.

All clinical covariates were significant at the univariate level with the exception of age at diagnosis $\left(\chi^{2}=1.09\right)$ and year of diagnosis $\left(\chi^{2}=1.06\right)$ (Table 1$)$. The univariate hazard ratio for a one-unit change in CAPRA was 1.40 (95\% CI $(1.28,1.52)$, $\left.\chi^{2}=65.0, P=7.8 \times 10^{-16}\right)$. We also considered CAPRA $(n=761)$ with imputed clinical stage $(n=173)$, PSA $(n=2)$, and extent of disease $(n=1)$, but this did not materially alter its univariate hazard ratio $\left(\mathrm{HR}=1.43,95 \% \mathrm{CI}(1.33,1.55), \chi^{2}=100.8, P=1.0\right.$ $\times 10^{-23}$ ). The CCP score was moderately correlated (Spearman's rank) with CAPRA $(\rho=0.4)$ and individual clinical factors: Gleason score $(\rho=0.4)$, PSA $(\rho=0.3)$, extent of disease $(\rho=0.3)$, and clinical stage $(\rho=0.3)$.

Multivariate analyses. In a predefined bivariate analysis, the CCP score retained significance when added to CAPRA $(\mathrm{HR}=1.76$, 95\% CI $(1.44,2.14), \Delta \chi^{2}=25.6, P=4.1 \times 10^{-7}$; Table 2). In the current cohort, the fitted coefficients for CCP and CAPRA were 0.56 and 0.26 , respectively, and were very similar to the prespecified values ( 0.57 and 0.39 , respectively). A full multivariate analysis with de novo treatment of the clinical parameters was also performed as the most conservative test of the independent prognostic information in the CCP score. In this model, the CCP score remained a highly significant predictor of prostate cancer death $\left(\mathrm{HR}=1.76,95 \% \mathrm{CI}(1.47,2.14), \Delta \chi^{2}=23.7, P=1.14 \times 10^{-6}\right)$ after adjusting for Gleason score (four levels), PSA (log-linear), percentage of positive needle cores (extent of disease), and clinical stage (three levels).

We found no evidence of an interaction between CCP and CAPRA, Gleason score, or PSA when an interaction term was added to separate bivariate survival analyses or in the de novo multivariate model.

CCR validation. A previously defined linear combination of CCP score and CAPRA (CCR score) was used. This score was highly significant for death from prostate cancer. The hazard ratio associated with a one-unit increase in the CCR score was 2.17 $\left(95 \% \mathrm{CI}=(1.83,2.57) \chi^{2}=88.9, P=4.1 \times 10^{-21}\right.$; Table 1$)$. No other variable added significant information to the predefined CCR score, except for a small effect of 'extent of disease' not fully captured by CAPRA $\left(\Delta \chi^{2}=6.82, P=0.01\right)$. However, this would not be significant if a Bonferroni correction was used to account for the six variables explored. The impact of this variable was greater than in our previous study (Cuzick et al, 2012) and probably reflects the greater number of needle biopsies taken in this cohort (mean 6.9 vs 3.1, $P=2.2 \times 10^{-16}$ ).

For predicting 10-year prostate cancer-specific mortality, the $c$ index for CAPRA was 0.74 and improved to 0.78 for CCR, further demonstrating that the addition of CCP adds significant risk stratification to what is available from clinicopathological variables alone. This compares favourably with a recent DNA-based test in patients treated by radical prostatectomy where biochemical recurrence was the end point (Cooperberg et al, 2006). The 10 -year risk of prostate cancer death as a function of CCR is shown in Figure 2 and is virtually identical to the 10-year risk curve derived from our previously published conservatively managed biopsy cohort, although the CCP score distribution was substantially lower (median 0.40 vs 1.03 ) in the current study.

Subgroup and exploratory analyses. The prognostic value of CCP stratified by CAPRA score and separate clinical variables is shown in Figure 3. No significant heterogeneity was observed. Effects of the CCP score were slightly stronger in years $0-5$, $(\mathrm{HR}=2.47,95 \%$ CI $(1.87,3.26))$, than for years $5-10(\mathrm{HR}=2.03,95 \% \mathrm{CI}(1.62$, $2.56)$ ), but the difference was not statistically significant $(P=0.3$, Table 2). No effect was seen after 10 years, but confidence intervals were wide $(\mathrm{HR}=1.3895 \% \mathrm{CI}(0.78,2.46))$.

Identification of a low-risk group suitable for active surveillance. CAPRA identified 80 men (13.7\%) in the low-risk group (0-2) and those with CAPRA $=2$ had a 10 -year prostate cancer mortality of $4.0 \%$. CCR indicated $11(14 \%)$ men in this group had a higher risk and identified a further $31(44 \%)$ men with CAPRA $=3$ but with a risk of $<4.0 \%$ using the combined CCR score. A dot plot (Figure 4) shows the predicted value of CAPRA alone vs the combined CCR score.

Comparison with other clinical scores. We evaluated two previously published clinical risk scores for prostate cancer mortality in patients managed conservatively. Both were highly correlated with CAPRA (Kattan (Kattan et al, 2008), $\rho=0.8$, Cuzick (Cuzick et al, 2006), $\rho=0.85$ ). The results were $\chi^{2}=61.3$, $P=4.8 \times 10^{-15}$ and $\chi^{2}=56.0, \quad P=7.4 \times 10^{-14}$, respectively, indicating similar predictive power for all three scores. The hazard ratio for adding the CCP score was very similar, regardless of which clinical score was used (CAPRA, HR=1.76; Kattan, $\mathrm{HR}=1.70$; Cuzick, $\mathrm{HR}=1.71$ ).

\section{DISCUSSION}

The goal of this study was to validate a predefined prognostic score (CCR) in order to help physicians select appropriate clinical management for patients with newly diagnosed clinically localised prostate cancer. These results confirm our previous findings for the 
Table 1. Univariate analysis for death from prostate cancer $(n=585)$

Univariate analysis

\begin{tabular}{|c|c|c|c|c|}
\hline Variable & No. of men (deaths) & Hazard ratio $(95 \% \mathrm{Cl})$ & $\chi^{2}(1 \mathrm{df})$ & $P$-value \\
\hline CCP (linear) & $585(100)$ & $2.08(1.76,2.46)$ & 56.4 & $6.0 \times 10^{-14}$ \\
\hline CCP (groups) & & & 64.9 & $7.8 \times 10^{-16}$ \\
\hline $\begin{array}{l}\leqslant 0 \\
>0-1 \\
>1-2 \\
>2\end{array}$ & $\begin{array}{r}194(12) \\
251(35) \\
110(39) \\
30(14)\end{array}$ & $\begin{array}{c}1 \text { (ref.) } \\
2.21(1.15,4.27) \\
6.84(3.57,13.1) \\
14.1(6.48,30.5)\end{array}$ & & \\
\hline Gleason score (linear) & $585(100)$ & $1.89(1.58,2.27)$ & 42.2 & $8.2 \times 10^{-11}$ \\
\hline Gleason (groups) & & & 45.5 & $1.5 \times 10^{-11}$ \\
\hline $\begin{array}{l}3+3 \\
3+4 \\
4+3 \\
>7\end{array}$ & $\begin{array}{l}151(5) \\
200(31) \\
126(30) \\
108(34)\end{array}$ & $\begin{array}{l}0.20(0.08,0.52) \\
1 \text { (ref.) } \\
1.60(0.96,2.65) \\
2.61(1.60,4.26)\end{array}$ & & \\
\hline $\log (1+P S A)\left(n g m^{-1}\right)$ & $585(100)$ & $2.07(1.61,2.65)$ & 34.0 & $5.6 \times 10^{-9}$ \\
\hline PSA (groups) (ng ml ${ }^{-1}$ ) & & & 32.4 & $1.2 \times 10-8$ \\
\hline $\begin{array}{l}\leqslant 4 \\
>4-10 \\
>10-25 \\
>25-50 \\
>50-100\end{array}$ & $\begin{array}{l}15(4) \\
175(9) \\
210(33) \\
103(28) \\
82(26)\end{array}$ & $\begin{array}{c}4.44(1.36,14.4) \\
1 \text { (ref.) } \\
3.33(1.59,6.98) \\
6.04(2.84,12.8) \\
7.88(3.69,16.8)\end{array}$ & & \\
\hline Extent of disease (\%) & & & 52.0 & $5.5 \times 10^{-13}$ \\
\hline $\begin{array}{l}<34 \\
34-<67 \\
67-<100 \\
100\end{array}$ & $\begin{array}{r}179(10) \\
176(22) \\
91(24) \\
139(44)\end{array}$ & $\begin{array}{l}0.48(0.22,1.02) \\
1 \text { (ref.) } \\
2.82(1.56,5.11) \\
3.49(2.06,5.93)\end{array}$ & & \\
\hline Age at diagnosis (years) & $585(100)$ & $1.02(0.98,1.06)$ & 1.09 & 0.30 \\
\hline Age (groups) (years) & & & 0.56 & 0.46 \\
\hline $\begin{array}{l}<60 \\
60-64 \\
>64-69 \\
>69\end{array}$ & $\begin{array}{c}32(3) \\
57(12) \\
142(25) \\
354(60)\end{array}$ & $\begin{array}{l}0.42 \text { (0.12, 1.48) } \\
1 \text { (ref.) } \\
0.86(0.43,1.72) \\
0.89(0.48,1.66)\end{array}$ & & \\
\hline Year of diagnosis & $585(100)$ & $0.94(0.85,1.04)$ & 1.40 & 0.24 \\
\hline Year of diagnosis & & & 1.09 & 0.3 \\
\hline 1999-2000 & $78(22)$ & $1.33(0.79,2.26)$ & & \\
\hline 2001-2003 & $507(78)$ & 1 (ref.) & & \\
\hline Clinical stage & & & 41.7 & $1.1 \times 10^{-10}$ \\
\hline $\begin{array}{l}1 \\
2 \\
3 / 4\end{array}$ & $\begin{array}{r}87(10) \\
371(43) \\
127(47)\end{array}$ & $\begin{array}{l}0.71(0.35,1.47) \\
1 \text { (ref.) } \\
3.90(2.58,5.91)\end{array}$ & & \\
\hline Initial hormones & & & 23.8 & $1.1 \times 10^{-6}$ \\
\hline $\begin{array}{l}\text { No } \\
\text { Yes }\end{array}$ & $\begin{array}{l}208(17) \\
377(83)\end{array}$ & $\begin{array}{c}1 \text { (ref.) } \\
3.20(1.90,5.41)\end{array}$ & & \\
\hline CAPRA (linear) & $585(100)$ & $1.40(1.28,1.52)$ & 65.0 & $7.8 \times 10^{-16}$ \\
\hline CAPRA (groups) & & & 64.1 & $1.2 \times 10^{-15}$ \\
\hline $\begin{array}{l}0-2 \\
3-5 \\
6-7 \\
8-10\end{array}$ & $\begin{array}{c}80(2) \\
207(16) \\
136(29) \\
162(53)\end{array}$ & $\begin{array}{l}0.30 \text { (0.07, 1.29) } \\
1 \text { (ref.) } \\
2.90(1.56,5.38) \\
5.49(3.14,9.62)\end{array}$ & & \\
\hline CCR (linear) & $585(100)$ & $2.17(1.83,2.57)$ & 88.9 & $4.1 \times 10^{-21}$ \\
\hline CCR (groups) & & & 63.4 & $1.7 \times 10^{-15}$ \\
\hline $\begin{array}{l}\leqslant 1 \\
>1-2 \\
>2-3 \\
>3\end{array}$ & $\begin{array}{c}92(2) \\
145(10) \\
133(21) \\
215(67)\end{array}$ & $\begin{array}{c}1 \text { (ref.) } \\
3.32(0.73,15.2) \\
8.08(1.89,34.5) \\
18.30(4.47,74.6)\end{array}$ & & \\
\hline
\end{tabular}




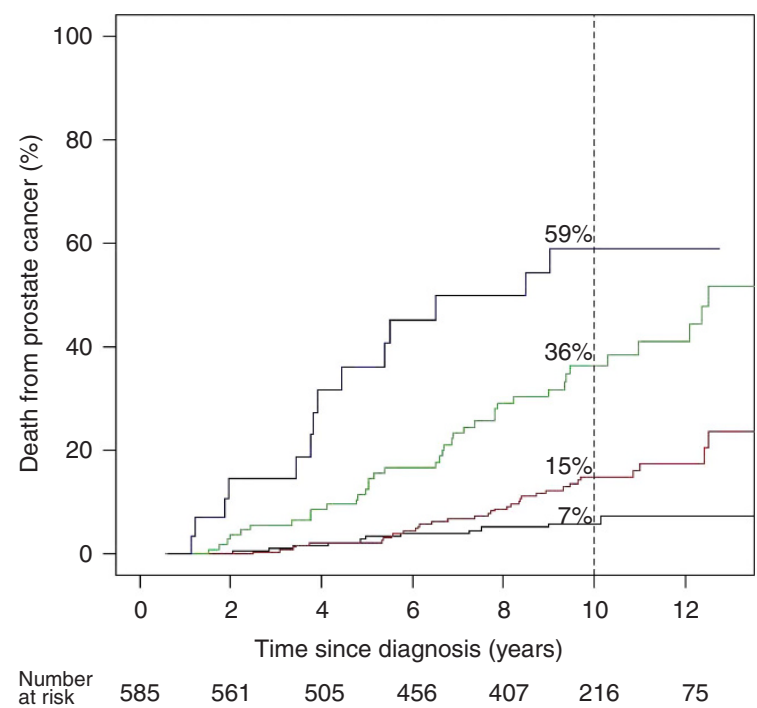

Figure 1. Kaplan-Meier estimates and log 10-year risk of prostate cancer death according to CCP score. Categories of CCP score are: $\mathrm{CCP} \leqslant 0(n=194$, black); $0<\mathrm{CCP} \leqslant 1(n=251$, red); $1<\mathrm{CCP} \leqslant 2$ ( $n=110$, green), and CCP $>2$ ( $n=30$, blue). prognostic value of the CCP score measured in diagnostic needle biopsies (Cuzick et al, 2012). For conservatively managed patients, the CCP score was highly prognostic for death from prostate cancer and provided important independent information that could not be obtained from clinical data. In addition, this study provides a fully independent validation in a new data set of a predefined CCR score as a linear combination of the CCP score and clinical variables (combined in the CAPRA score), which almost completely accounted for all molecular and clinical prognostic information. Further work is needed to determine if DNA based (Lalonde et al, 2014) or other markers can add useful information to our combined score.

The results presented here also establish the clear added prognostic value of the CCP score beyond that obtained from CAPRA, a well-established score for classical clinicopathological variables. Similar added value of the CCP score was seen when either the Kattan nomogram or Cuzick score was used for the classical variables. We used CAPRA in this study to account for the clinical information, because it has been extensively validated on thousands of patients (Cooperberg et al, 2006; May et al, 2007; Zhao et al, 2008) and its derivation is simple and transparent.

Of interest is that the CCP score could be generated with as little as $0.5-\mathrm{mm}$ tumour evident on diagnostic $\mathrm{H} \& \mathrm{E}$ from a single positive needle biopsy core. Here, we used archival samples, $>10$

Table 2. Univariate analysis of risk scores and bivariate analysis of CCP score with CAPRA score for death from prostate cancer and added value of CCP to CAPRA in the time intervals: 0-5 years, 5-10 years, and $>10$ years

\begin{tabular}{|c|c|c|c|c|c|c|c|}
\hline & & \multicolumn{3}{|c|}{ Univariate analysis } & \multicolumn{3}{|c|}{ Bivariate analysis } \\
\hline Variable & $\begin{array}{l}\text { No. of men } \\
\text { (deaths) }\end{array}$ & $\chi^{2}(1 \mathrm{df})$ & $\begin{array}{c}\text { Hazard ratio } \\
(95 \% \mathrm{Cl})\end{array}$ & $P$-value & $\Delta \chi^{2}(1 \mathrm{df})$ & $\begin{array}{c}\text { Hazard ratio } \\
(95 \% \mathrm{Cl})\end{array}$ & $P$-value \\
\hline \multicolumn{8}{|c|}{ CCP score } \\
\hline $\begin{array}{l}\text { Overall } \\
0-5 \text { years } \\
5-10 \text { years } \\
>10 \text { years }\end{array}$ & $\begin{array}{l}585(100) \\
585(33) \\
483(54) \\
216(13)\end{array}$ & $\begin{array}{c}56.4 \\
31.1 \\
28.0 \\
1.08\end{array}$ & $\begin{array}{l}2.08(1.76,2.46) \\
2.47(1.87,3.26) \\
2.03(1.62,2.56) \\
1.38(0.78,2.46)\end{array}$ & $\begin{array}{c}6.0 \times 10^{-14} \\
2.5 \times 10^{-8} \\
1.2 \times 10^{-7} \\
0.30\end{array}$ & $\begin{array}{c}25.6 \\
15.2 \\
12.3 \\
0.28\end{array}$ & $\begin{array}{l}1.76(1.44,2.14) \\
2.09(1.49,2.94) \\
1.71(1.30,2.26) \\
1.20(0.63,2.28)\end{array}$ & $\begin{array}{l}4.2 \times 10^{-7} \\
9.9 \times 10^{-5} \\
0.00046 \\
0.60\end{array}$ \\
\hline \multicolumn{8}{|c|}{ CAPRA score } \\
\hline $\begin{array}{l}\text { Overall } \\
0-5 \text { years } \\
5-10 \text { years } \\
>10 \text { years }\end{array}$ & $\begin{array}{l}585(100) \\
585(33) \\
483(54) \\
216(13)\end{array}$ & $\begin{array}{c}65.1 \\
29.0 \\
34.0 \\
3.58\end{array}$ & $\begin{array}{l}1.40(1.28,1.52) \\
1.49(1.27,1.75) \\
1.38(1.23,1.55) \\
1.26(0.98,1.60)\end{array}$ & $\begin{array}{c}6.7 \times 10^{-16} \\
7.4 \times 10^{-8} \\
5.6 \times 10^{-9} \\
0.058\end{array}$ & $\begin{array}{c}34.3 \\
13.0 \\
18.3 \\
2.73\end{array}$ & $\begin{array}{l}1.29(1.18,1.42) \\
1.33(1.12,1.58) \\
1.28(1.14,1.45) \\
1.23(0.96,1.59)\end{array}$ & $\begin{array}{c}4.6 \times 10^{-9} \\
3.0 \times 10^{-4} \\
1.9 \times 10^{-5} \\
0.096\end{array}$ \\
\hline
\end{tabular}
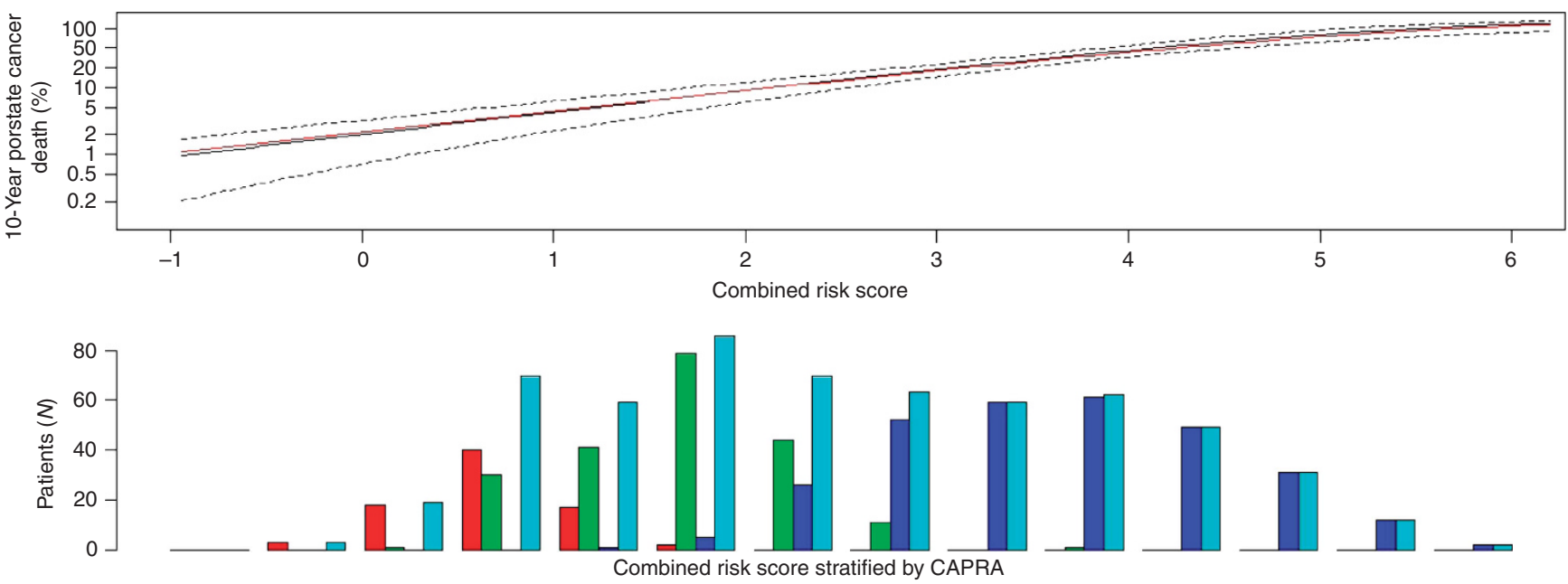

Figure 2. Ten-year predicted risk of prostate cancer death according to combined clinical-cell-cycle-risk score. (Top) current cohort (black), earlier cohort, Cuzick et al (2012) (red), 95\% Cls for current cohort (dashed). (Bottom) Histogram of CCR score in different CAPRA categories: 0-2 (red), 35 (green), 6-10 (blue), All (turquoise). 


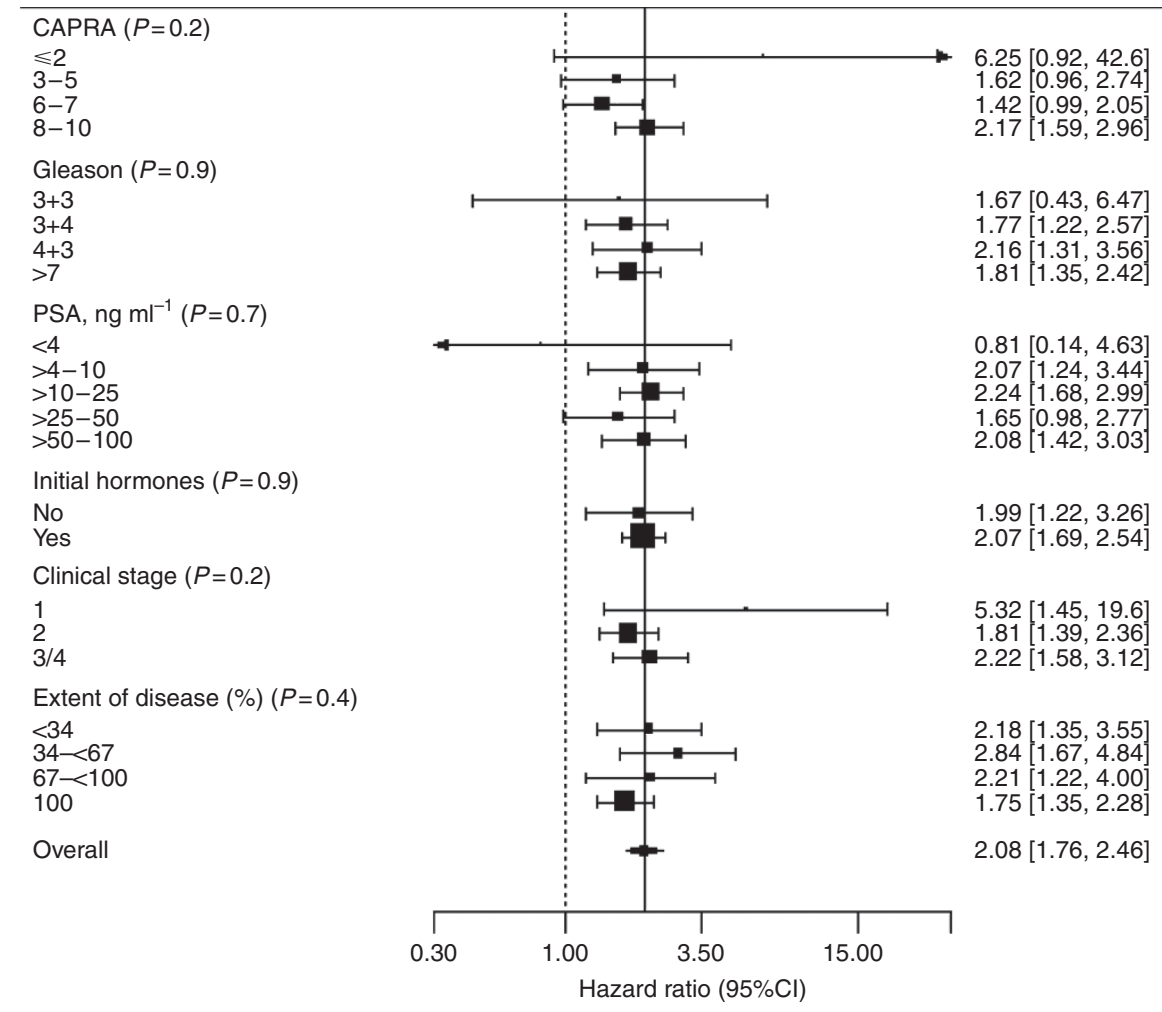

Figure 3. Hazard ratio and $95 \% \mathrm{Cls}$ (censored at 10 years) for prostate cancer death for a one unit change in CCP score for different clinical subgroups and CAPRA risk groups. P-values after each variable indicate significance of a test for heterogeneity.

years old, and the assay success rate was $77 \%$ overall and $90 \%$ when $>0.5 \mathrm{~mm}$ of tumour was visible on the matched H\&E section. However, higher success rates are seen in data from the Myriad commercial laboratory (95.3\% for all tests in 2013), with little variation between triplicate quantitative laboratory tests. Also, unlike Gleason grading, the CCP score has no subjective component.

The strengths of this study include complete long follow-up, contemporary path review of Gleason grade, a definitive end point (10-year mortality from prostate cancer) and a completely independent validation cohort with fully prespecified objective end points and prespecified analysis algorithms. Limitations are that these were all symptomatic patients with a worse average prognosis than for contemporary cohorts of mostly screen-detected cancers, and changes in treatment $\geqslant 6$ months after diagnosis were not documented, except in part of one registry where patient notes were reviewed for 170 men. In that group, about $45 \%$ of the men had either a prostatectomy or radiotherapy by month 24 , but we found it extremely difficult to determine if subsequent treatment was due to disease progression, patient anxiety, or both. This rate of treatment is not unexpected given that the cohort contained men across all risk categories. For typical active surveillance cohorts containing low-risk men only, about one-third of patients opt for definitive treatment within 2 years (Cooperberg et al, 2011; Dall'Era et al, 2012). Although objectively identified form cancer registries, this was a retrospective cohort, as any prospective study would take 10 years to accrue the follow-up needed for our end point. Cause of death was ascertained from death certificates only by registry staff, but no relationship between death from other causes and the CCP score (or CCR and CAPRA when age was allowed for) was seen, suggesting that there was little misclassification of cause of death.

We found that all of the predictive information in the CCP score and the clinicopathological variables was captured by the CCR score. For men with Gleason 3+3, the observed 10-year mortality was low $(3.1 \%)$ in our cohort so precise estimates in this group are

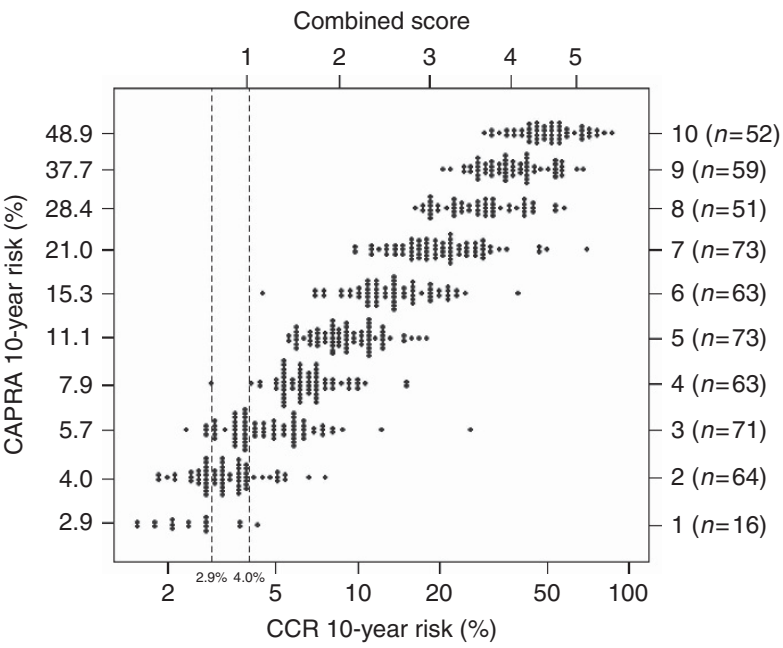

Figure 4. Dot plot showing the predicted 10-year risk of death from prostate cancer based on the combined clinical-cell-cycle-risk (CCR) score and CAPRA score. Each dot represents the individual predicted risk for CAPRA alone vs CCR score.

not possible. In 2004-2007, at least $80 \%$ of such patients received radical treatment in the United States (Cooperberg et al, 2013), and the CCP score may be useful to support active surveillance for these patients. The CCR score classified $63 \%$ of patients with Gleason $3+3$ as having a 10 -year mortality of $<5 \%$, whereas CAPRA identified only $46 \%$ in this group. For men with Gleason $3+4$, where the 10 -year disease specific mortality was $15.5 \%$, the CCP provides very useful prognostic information for decision making. This was also true for CAPRA scores of 2 or 3 where the 10 -year risk was $4.0 \%$ and $5.7 \%$, respectively. For higher CAPRA scores or Gleason scores, most patients would need radical 
treatment, but the CCP score can also help in determining the need for adjuvant endocrine or chemotherapy.

\section{ACKNOWLEDGEMENTS}

We thank investigators and staff in the cancer registries and participating hospitals (Supplementary Appendix) for their support. We thank also Dr Kathryn Kolquist (Myriad Genetics) for pathology support. We gratefully acknowledge support from Cancer Research UK, ORCHID, National Institutes of Health (SPORE), the Koch Foundation and Myriad Genetics. This work was supported by Cancer Research UK, Queen Mary University of London, Orchid Appeal, US National Institutes of Health, and Koch Foundation.

\section{CONFLICT OF INTEREST}

Dr Lanchbury, Dr Gutin, Dr Brawer, Dr Stone, and Ms Reid are employees of Myriad Genetics. Professor Cuzick is a member of the Myriad speaker's bureau. No other authors report any conflict of interest. Myriad Genetics have provided funding support to Queen Mary University of London to facilitate preparation of tumour blocks. The cell cycle expression profiles were assayed blind to all other data by Myriad Genetics. Analysis was conducted at QMUL under the direction of Professor Cuzick, following a predefined Statistical Analysis Plan. Professor Cuzick had full access to all of the data in the study and takes responsibility for the integrity of the data and the accuracy of the data analysis. Interpretation of the data was done jointly by all authors, but the final content of this report was determined by non-corporate authors.

\section{REFERENCES}

Albertsen JL, Hanley JA, Gleason DF, Barry MJ (1998) Competing risk analysis of men aged 55 to 74 years at diagnosis managed conservatively for clinically localized prostate cancer. JAMA 280: 975-980.

Albertsen PC, Hanley JA, Fine J (2005) 20-year outcomes following conservative management of clinically localized prostate cancer. JAMA 293(17): 2095-2101.

Andriole GL, Crawford ED, Grubb 3rd RL, Buys SS, Chia D, Church TR, Fouad MN, Gelmann EP, Kvale PA, Reding DJ, Weissfeld JL, Yokochi LA, O'Brien B, Clapp JD, Rathmell JM, Riley TL, Hayes RB, Kramer BS, Izmirlian G, Miller AB, Pinsky PF, Prorok PC, Gohagan JK, Berg CD. PLCO Project Team (2009) Mortality results from a randomized prostate-cancer screening trial. N Engl J Med 360(13): 1310-1319.

Bishoff JT, Freedland SJ, Gerber L, Tennstedt P, Reid J, Welbourn W, Graefen M, Sangale Z, Tikishvili E, Park J, Younus A, Gutin A, Lanchbury JS, Sauter G, Brawer M, Stone S, Schlomm T (2014) Prognostic utility of the CCP score generated from biopsy in men treated with prostatectomy. J Urol 192(2): 409-414.

Brawer MK, Cooperberg MR, Freedland SJ, Swanson GP, Stone S, Reid JE, Gutin A, Carroll P, Cuzick JM (2013) Development and validation of a multivariate model combining cell cycle progression score with CAPRA to predict prostate cancer mortality in a conservatively managed cohort. J Clin Oncol 31: 6s (suppl; abstr 67).

Cooperberg MR, Pasta DJ, Elkin EP, Litwin MS, Latini DM, Du Chane J, Carroll PR (2005) The University of California, San Francisco Cancer of the Prostate Risk Assessment score: a straightforward and reliable preoperative predictor of disease recurrence after radical prostatectomy. J Urol 173(6): 1938-1942.

Cooperberg MR, Freedland SJ, Pasta DJ, Elkin EP, Presti Jr JC, Amling CL, Terris MK, Aronson WJ, Kane CJ, Carroll PR (2006) Multi-institutional validation of the UCSF cancer of the prostate risk assessment for prediction of recurrence after radical prostatectomy. Cancer 107(10): 2384-2391.

Cooperberg MR, Broering JM, Carroll PR (2009) Risk assessment for prostate cancer metastasis and mortality at the time of diagnosis. J Natl Cancer Inst 101: 878-887.

Cooperberg MR, Carroll PR, Klotz L (2011) Active surveillance for prostate cancer: progress and promise. J Clin Oncol 29: 3669-3676.

Cooperberg MR, Simko JP, Cowan JE, Reid JE, Djalilvand A, Bhatnagar S, Gutin A, Lanchbury JS, Swanson GP, Stone S, Carroll PR (2013) Validation of a cell-cycle progression gene panel to improve risk stratification in a contemporary prostatectomy cohort. J Clin Oncol 31(11): $1428-1434$.

Cuzick J, Fisher G, Kattan MW, Berney D, Oliver T, Foster CS, Møller H, Reuter V, Fearn P, Eastham J, Scardino P. Transatlantic Prostate Group (2006) Long-term outcome among men with conservatively treated localised prostate cancer. Br J Cancer 95: 1186-1194.

Cuzick J, Swanson GP, Fisher G, Brothman AR, Berney DM, Reid JE, Mesher D, Speights VO, Stankiewicz E, Foster CS, Møller H, Scardino P, Warren JD, Park J, Younus A, Flake 2nd DD, Wagner S, Gutin A, Lanchbury JS, Stone S. Transatlantic Prostate Group (2011) Prognostic value of an RNA expression signature derived from cell cycle proliferation genes in patients with prostate cancer: a retrospective study. Lancet Oncol 12(3): 245-255.

Cuzick J, Berney DM, Fisher G, Mesher D, Møller H, Reid JE, Perry M, Park J, Younus A, Gutin A, Foster CS, Scardino P, Lanchbury JS, Stone S. Transatlantic Prostate Group (2012) Prognostic value of a cell cycle progression signature for prostate cancer death in a conservatively managed needle biopsy cohort. Br J Cancer 106: 1095-1099.

Cuzick J, Thorat MA, Andriole G, Brawley OW, Brown PH, Culig Z, Eeles RA, Ford LG, Hamdy FC, Holmberg L, Ilic D, Key TJ, La Vecchia C, Lilja H, Marberger M, Meyskens FL, Minasian LM, Parker C, Parnes HL, Perner S, Rittenhouse H, Schalken J, Schmid HP, Schmitz-Dräger BJ, Schröder FH, Stenzl A, Tombal B, Wilt TJ, Wolk A (2014) Prevention and early detection of prostate cancer. Lancet Oncol 15(11): e484-e492.

Dall'Era MA, Albertsen PC, Bangma C, Carroll PR, Carter HB, Cooperberg MR, Freedland SJ, Klotz LH, Parker C, Soloway MS (2012) Active surveillance for prostate cancer: a systematic review of the literature. Eur Urol 62: 976-983.

Epstein JI, Allsbrook Jr WC, Amin MB, Egevad LL. ISUP Grading Committee (2005) The 2005 International Society of Urological Pathology (ISUP) Consensus Conference on Gleason Grading of Prostatic Carcinoma. Am J Surg Pathol 29(9): 1228-1242.

Epstein JI (2010) An update of the Gleason grading system. J Urol 183(2): 433-440.

Freedland SJ, Gerber L, Reid J, Welbourn W, Tikishvili E, Park J, Younus A, Gutin A, Sangale Z, Lanchbury JS, Salama JK, Stone S (2013) Prognostic utility of cell cycle progression score in men with prostate cancer after primary external beam radiation therapy. Int J Radiat Oncol Biol Phys 86(5): 848-853.

Kattan MW, Cuzick J, Fisher G, Berney DM, Oliver T, Foster CS, Møller H, Reuter V, Fearn P, Eastham J, Scardino PT. Transatlantic Prostate Group (2008) Nomogram incorporating PSA level to predict cancer-specific survival for men with clinically localized prostate cancer managed without curative intent. Cancer 112(1): 69-74.

Lalonde E, Ishkanian AS, Sykes J, Fraser M, Ross-Adams H, Erho N, Dunning MJ, Halim S, Lamb AD, Moon NC, Zafarana G, Warren AY, Meng X, Thoms J, Grzadkowski MR, Berlin A, Have CL, Ramnarine VR, Yao CQ, Malloff CA, Lam LL, Xie H, Harding NJ, Mak DY, Chu KC, Chong LC, Sendorek DH, P’ng C, Collins CC, Squire JA, Jurisica I, Cooper C, Eeles R, Pintilie M, Dal Pra A, Davicioni E, Lam WL, Milosevic M, Neal DE, van der Kwast T, Boutros PC, Bristow RG (2014) Tumour genomic and microenvironmental heterogeneity for integrated prediction of 5-year biochemical recurrence of prostate cancer: a retrospective cohort study. Lancet Oncol 15(13): 1521-1532.

May M, Knoll N, Siegsmund M, Fahlenkamp D, Vogler H, Hoschke B, Gralla O (2007) Validity of the CAPRA score to predict biochemical recurrence-free survival after radical prostatectomy. Results from a European multicenter survey of 1,296 patients. J Urol 178(5): 1957-1962.

Moyer VA. U.S. Preventive Services Task Force (2012) Screening for prostate cancer: U.S. Preventive Services Task Force recommendation statement. Ann Intern Med 157(2): 120-134. 
Schröder FH, Hugosson J, Roobol MJ, Tammela TL, Ciatto S, Nelen V, Kwiatkowski M, Lujan M, Lilja H, Zappa M, Denis LJ, Recker F, Páez A, Määttänen L, Bangma CH, Aus G, Carlsson S, Villers A, Rebillard X, van der Kwast T, Kujala PM, Blijenberg BG, Stenman UH, Huber A, Taari K, Hakama M, Moss SM, de Koning HJ, Auvinen A. ERSPC Investigators (2012) Prostate-cancer mortality at 11 years of follow-up. N Engl J Med 366(11): 981-990Erratum in: N Engl J Med May 31;366(22):2137.

Sommariva S, Tarricone R, Lazzeri M, Ricciardi W, Montorsi F (2014) Prognostic value of the cell cycle progression score in patients with prostate cancer: a systematic review and meta-analysis. Eur Urol; e-pub ahead of print 4 December 2014; doi:10.1016/j.eururo.2014.11.038.
WHO (2010) International statistical classification of diseases and related health problems. 10th revision, 4th edition ISBN 978924154834 2. http:// www.who.int/classifications/icd/ICD10Volume2_en_2010.pdf.

Zhao KH, Hernandez DJ, Han M, Humphreys EB, Mangold LA, Partin AW (2008) External validation of University of California, San Francisco, Cancer of the Prostate Risk Assessment score. Urology 72(2): 396-400.

cc)(i) (2) This work is licensed under the Creative Commons Attribution-Non-Commercial-Share Alike 4.0 International License. To view a copy of this license, visit http:// creativecommons.org/licenses/by-nc-sa/4.0/

Supplementary Information accompanies this paper on British Journal of Cancer website (http://www.nature.com/bjc) 